\title{
Traceability systems and its impact on the farming community of Southern Tamil Nadu
}

\author{
P. Muthupandi*, C. Sekhar and K. R. Karunakaran \\ Department of Agricultural Economics, Tamil Nadu Agricultural University, Coimbatore (T.N.) India \\ (Email: saekarck@gmail.com)
}

\begin{abstract}
The international organization for standardization has defined the traceability as the ability to follow the movement of food or feed through the specified stages of production, processing and distribution.Chilli is one of the principal spice exported to several countries during the pre and post-globalization era. Pesticide residues and presence of Aflatoxins in the samples of chilli cautioned the import destinations to choose the concept of traceability. Traceability addresses the hygienic production, processing and value addition practices stage by stage and framed certain minimum standards for export of chilli. Following the standards, how the traceability is addressed from farm to fork is discussed in detail and at the same time the socio-economic impact of traceability is also addressed for redefining the trade.
\end{abstract}

Key Words : Traceability, Traceability systems, Value chain, Socio-economic impact of farming community

View Point Article : Muthupandi, P., Sekhar, C. and Karunakaran, K.R. (2019). Traceability systems and its impact on the farming community of Southern Tamil Nadu. Internat. J. agric. Sci., 15 (1) : 1-14, DOI:10.15740/HAS/IJAS/15.1/1-14. Copyright@ 2019: Hind Agri-Horticultural Society.

Article History : Received : 17.10.2018; Revised : 15.11.2018; Accepted : 21.11.2018

\footnotetext{
* Author for correspondence:
} 